\title{
Packed Red Blood Cell Supernatants Do Not Promote Growth or Cisplatin Resistance of Myeloid Leukemia K-562 Cells
}

\author{
Kamila Czubak-Prowizor $\mathbb{D}^{1,2}$, Anna Macieja ${ }^{3}$, Tomasz Poplawski ${ }^{4}$, Halina Malgorzata Zbikowska' \\ 'Department of General Biochemistry, Faculty of Biology and Environmental Protection, University of Lodz, Lodz, 90-236, Poland; ${ }^{2}$ Department of \\ Cytobiology and Proteomics, Medical University of Lodz, Lodz, 92-215, Poland; ${ }^{3}$ Department of Molecular Genetics, Faculty of Biology and \\ Environmental Protection, University of Lodz, Lodz, 90-236, Poland; ${ }^{4}$ Department of Chemistry and Clinical Biochemistry, Medical University of Lodz, \\ Lodz, 90-136, Poland \\ Correspondence: Kamila Czubak-Prowizor, Department of General Biochemistry, Faculty of Biology and Environmental Protection, University of \\ Lodz, Pomorska I4I/I43, Lodz, 90-236, Poland, Tel +48 4263544 83, Email kamila.czubak@biol.uni.lodz.pl; kamila.czubak-prowizor@umed.lodz.pl
}

Background: A decreased immune surveillance as a consequence of packed red blood cell (PRBC) transfusions has been linked to cancer recurrence and progression, but a causal mechanism remains unclear. During processing and storage of PRBC, numerous bioactive substances accumulate in the acellular fraction (supernatant) of PRBC.

Aim: The study aimed to determine whether the supernatant of leukocyte-reduced (LR) and non-leukocyte-reduced (NLR) long-stored PRBC can modulate the survival and proliferation of myeloid leukemia K-562 cells, and the influence of cisplatin (cisPt) on these processes.

Methods: Viability, proliferation, DNA damage, intracellular reactive oxygen species (ROS), caspase-3/7 and caspase-9 levels were determined in response to the LR or NLR, fresh (day 1) and long-stored (day 42) PRBCs.

Results: The supernatants of fresh (day 1) and stored (day 42) PRBC, in the absence and presence of cisPt, promoted apoptosis of K-562 cells via the increased production of reactive oxygen species (ROS) and increased level of DNA damage, which was manifested by the viability reduction and inhibition of K-562 cell proliferation. No significant influence of the pre-storage leukocyte-filtration and storage time of PRBC units on their anti-proliferative effect was demonstrated.

Conclusion: The findings may suggest that the PRBC acellular fraction does not affect chronic myeloid leukemia (CML) progression. However, these issues are pioneering and require further study.

Keywords: red blood cell, transfusion, myeloid leukemia, K-562 cells, cisplatin

\section{Introduction}

Anemia (defined as hemoglobin (Hb) levels below the normal value) is a common cancer-related complication, which can be caused by cancer itself, as occurs in blood malignancies as a result of the bone marrow infiltration by the malignant cells, and/or by a side effect of a high-dose chemotherapy. ${ }^{1}$ Therefore, patients with some hematologic malignancies, such as acute myeloid leukemia (AML) require frequent packed red blood cell (PRBC) transfusions. ${ }^{2}$ Although essentially safe, PRBC transfusion is often associated with the significant risks of severe post-transfusion reactions such as, among others, transfusion-related immune modulation (TRIM). ${ }^{3}$

A decreased immune surveillance as a consequence of blood transfusions has been linked to cancer recurrence and progression. Moreover, soluble factors present in PRBC can directly stimulate tumor growth and spread. ${ }^{4}$ An association between perioperative transfusion of allogeneic blood products and risk for recurrence has been proved in colorectal ${ }^{5-7}$ and a few other cancers, ${ }^{8}$ but the mechanism of this phenomenon has not been clarified yet. There are also some controversial studies not confirming such relationships in many types of cancer. ${ }^{8}$ 
Upon processing and routine storage, red blood cells undergo numerous biochemical and physiological changes with the concomitant release of numerous, potentially hazardous, bioactive substances (ie, extracellular $\mathrm{Hb}$, heme, iron, proteolytic enzymes, pro-inflammatory cytokines, chemokines, immunomodulating and vasoactive mediators, lipids and microparticles (MPs), mainly released from erythrocytes) into the acellular fraction of the PRBC unit. ${ }^{9}$ Pre-storage leukoreduction reduces $3 \operatorname{logs}(99.9 \%)$ leukocyte numbers ${ }^{10}$ which significantly decreases the accumulation of metabolites and cellular components into the PRBC unit. ${ }^{11}$

K-562 is the human erythroleukemia cell line of CML in the blast phase having the Philadelphia chromosome (Ph), caused by the $\mathrm{t}(9: 22)$ chromosomal reciprocal translocation which produces the $B C R-A B L 1$ fusion gene. The product of this gene, the chimeric BCR-ABL1 protein $\left(\mathrm{p} 210^{\mathrm{BCR}-\mathrm{ABL}}\right)$ is characterized by deregulated, constitutively activated tyrosine kinase and plays an important role in the induction of CML. ${ }^{12}$ Cisplatin, $\mathrm{PtCl}_{2}\left(\mathrm{NH}_{3}\right)_{2}$, (cisPt) is a cytostatic drug, commonly applied in laboratory research that has also been clinically used with some success in the chemotherapy of several types of malignant tumors. ${ }^{13}$ Cisplatin has been shown to induce apoptosis in CML cells. ${ }^{14}$

To the best of our knowledge, only a few previous reports have evaluated the response of cancer cells to PRBC. ${ }^{15,16}$ Moreover, no previous study has addressed its influence on the anti-proliferative effects of anti-neoplastics. This in vitro study was designed in a classic model system applying K-562 cells (widely used as a "workhorse" cell line) and cisPt (one of the most known anti-cancer drugs) which have commonly been used in biomedical research. The aim of the study was to determine whether the progressive changes occurring in long-stored PRBC (42 days established as an acceptable norm) can modulate the survival and proliferation of K-562 cells, and the influence of leukoreduction on these processes. To achieve this goal, we evaluated the effect of the acellular fraction (supernatant) of the fresh (day 1) and stored (day 42) PRBC, that had been pre-storage leukoreduced or the non-leukoreduced, on the viability and proliferation of K-562 cells, as well as on DNA damage, ROS levels, and apoptosis, in the absence and presence of cisPt.

\section{Materials and Methods}

\section{Reagents}

Cell Counting Kit-8 (CCK-8), cisplatin (cisPt), Cell Proliferation ELISA - BrdU colorimetric Kit (Roche), DAPI (4',6diamidino-2-phenylindole dihydrochloride), 2',7'-dichlorofluorescin diacetate $\left(\mathrm{H}_{2} \mathrm{DCF}-\mathrm{DA}\right)$, penicillin-streptomycin solution, normal melting-point agarose (NMP), RPMI-1640 medium with L-glutamine, Triton ${ }^{\mathrm{TM}} \mathrm{X}-100$, hydrogen peroxide, and low melting-point agarose (LMP) were purchased from Sigma-Aldrich Chemicals (St. Louis, MO, USA). Dulbecco's Phosphate Buffered Saline without calcium and magnesium (DPBS), Hanks BSS (HBSS) without phenol red with calcium and magnesium were purchased from Biological Industries (Cromwell, CT, USA), and heatinactivated fetal bovine serum (FBS) from Biowest (Nuaillé, France). All other analytical grade and high-quality chemicals were obtained from local commercial suppliers, such as Chempur (Piekary Slaskie, Poland) or POCH S.A. (Gliwice, Poland).

\section{Packed Red Blood Cells}

Five SAGM-preserved PRBC transfusion units were purchased from the Regional Blood Donation and Blood Treatment Centre in Lodz (Poland). Each of the SAGM-preserved non-leukoreduced (NLR; leukocytes $<10 \%$ unit) PRBCs, prepared in accordance with the standard procedures currently applied in blood banks, were divided into four equal aliquots by transferring them to the transfer bags in a closed system. Leukocytes from two transfer bags were removed during the gravity filtration process using a leukocyte depletion filter (BioR Flex, Fresenius Kabi AG, Bad Homburg, Germany) to obtain the pre-storage leukoreduced PRBC (LR; leukocytes $<10^{6} /$ unit), the other two transfer bags were left unfiltered. All processes were carried out under sterile conditions in the Regional Blood Donation and Blood Treatment Centre (Lodz). The NLR and LR PRBC had been stored, for 1 day or 42 days, at $4 \pm 2^{\circ} \mathrm{C}$. This study was approved by the University of Lodz Research Ethics Committee (no. 26/KBBN-UŁ/I/2017). 


\section{Supernatants from Stored PRBC}

Supernatants from PRBC, both NLR and LR, on day 1 (sNLR1 and SLR1, respectively) and on day 42 of storage (sNLR42 and sLR42) were obtained in accordance with the method described by Westerman et al ${ }^{17}$ Briefly, PRBC units were centrifuged at $2000 \mathrm{~g}$ for $10 \mathrm{~min}$ at $4^{\circ} \mathrm{C}$, the supernatants were removed and spun at $3000 \mathrm{~g}$ for $10 \mathrm{~min}$ at $4^{\circ} \mathrm{C}$. Supernatants received by this method contain erythrocyte-derived microparticles (EMPs). Supernatants from PRBC were filtered through a syringe PES filter membrane with pore size $0.22 \mu \mathrm{m}$ (TPP Techno Plastic Products AG, Switzerland), aliquoted, and stored at $-70^{\circ} \mathrm{C}$.

\section{Cell Culture and Treatment}

Human chronic myelogenous leukemia cell line (K-562; ATCC $^{\circledR}$ CCL-243 ${ }^{\mathrm{TM}}$ ) was obtained from the American Type Culture Collection (ATCC; Manassas, VA, USA). Cells were grown in RPMI-1640 medium supplemented with 10\% heat-inactivated FBS and 1\% penicillin-streptomycin solution (10,000 units penicillin and $10 \mathrm{mg}$ streptomycin/mL) in a humidified atmosphere with $5 \% \mathrm{CO}_{2}$ at $37^{\circ} \mathrm{C}$.

For each experiment, cells were seeded on 96-well tissue culture plates and grown for $24 \mathrm{~h}$ in a complete culture medium supplemented with $5 \%$ (in some experiments also 10 and $20 \%$ ) by volume of PRBC supernatants (sNLR1, sLR1, sNLR42, sLR42) or with medium alone as a control, in the presence or absence of cisPt. The optimal concentration of cisPt $(10 \mu \mathrm{M})$ used in experiments was determined experimentally. First, $\mathrm{IC}_{50}$ was determined for the K-562 cell line, then a 2 -fold lower cisPt concentration $\left(1 / 2 \mathrm{IC}_{50}\right)$ was finally used in each experiment.

\section{Cell Viability}

The colorimetric assay, cell counting kit-8 (CCK-8), was conducted to assess cytotoxicity after treatment with the supernatants. K-562 cells (5000 per well) were grown in 96-well plates for $24 \mathrm{~h}$, then the supernatants and cisPt (where needed) were added to fresh culture medium in the plates. After $24 \mathrm{~h}$, cells were washed twice with DPBS, then $100 \mu \mathrm{L}$ of fresh media and CCK-8 solution $(10 \mu \mathrm{L})$ were added to each well, followed by incubation for $4 \mathrm{~h}$, at $37^{\circ} \mathrm{C}$ with $5 \%$ $\mathrm{CO}_{2}$. The absorbance at $450 \mathrm{~nm}$ was determined in the microplate reader SPECTROstar ${ }^{\circledR}$ Nano (BMG LABTECH $\mathrm{GmbH}$, Ortenberg, Germany). Cell viability was expressed as a percentage of the control (untreated) cells.

\section{Proliferation Assay}

For the quantification of K-562 cell proliferation, the bromodeoxyuridine (BrdU) proliferation assay was performed with a commercially available kit (BrdU colorimetric Kit, Roche) following the manufacturer's instruction. The absorbance at $370 \mathrm{~nm}$ and $492 \mathrm{~nm}$ (reference wavelength) were measured in the microplate reader SPECTROstar ${ }^{\circledR}$ Nano. Cell proliferation was expressed as a percentage of the untreated cells.

\section{Comet Assay}

The genotoxic effect of PRBC supernatants was assessed by the comet assay performed under alkaline conditions according to the procedure of Singh et al ${ }^{18}$ with some modifications. ${ }^{19} \mathrm{~K}-562$ cells were incubated for 60 min at $37^{\circ} \mathrm{C}$ with 5 and $20 \%$ of the supernatants. Cells suspended in fresh culture medium served as a negative control. Positive control was prepared by treating cells with $10 \mu \mathrm{M}$ hydrogen peroxide. After incubation, supernatants were removed by centrifugation (180 g, $15 \mathrm{~min}$, ambient temperature). Pellet of cells was suspended in 1.0\% LMP agarose and spread onto microscope slides pre-coated with $0.5 \%$ NMP agarose. Next, the cells were lysed for $1 \mathrm{~h}$, at $4^{\circ} \mathrm{C}$ in a lysis buffer $(2.5 \mathrm{M}$ $\mathrm{NaCl}, 100 \mathrm{mM}$ EDTA, 1\% Triton X-100, $10 \mathrm{mM}$ Tris, $\mathrm{pH} \mathrm{10).} \mathrm{All} \mathrm{remaining} \mathrm{steps} \mathrm{including} \mathrm{electrophoresis,} \mathrm{DAPI}$ comet staining, and measuring were performed according to Czubatka et al. ${ }^{20}$

\section{ROS Level}

The intracellular ROS levels were measured using the spectrofluorimetric method with the $\mathrm{H}_{2}$ DCF-DA fluorescent probe. ${ }^{21} \mathrm{~K}-562$ cells (5000 per well) were centrifuged (1500 g, $5 \mathrm{~min}$ ) and then the pellet was suspended in HBSS with $10 \mu \mathrm{M} \mathrm{H}_{2}$ DCF-DA ( $30 \mathrm{~min}, 37^{\circ} \mathrm{C}, 5 \% \mathrm{CO}_{2}$ ). The fluorescent probe was removed, and cells were washed twice with HBSS. Cells were re-suspended in the washing buffer and seeded on a 96-well black bottom microplate. The PRBC 
supernatants and cisPt (where needed) to the final concentration of $10 \mu \mathrm{M}\left(1 / 2 \mathrm{IC}_{50}\right)$ were added into wells. Cells treated with $10 \mu \mathrm{M} \mathrm{H}_{2} \mathrm{O}_{2}$ were used as positive controls, cells suspended in HBSS (untreated) as negative controls. After incubation $\left(60 \mathrm{~min}, 37^{\circ} \mathrm{C}\right)$, fluorescence intensity was read at $\lambda_{\mathrm{ex}}=485 \mathrm{~nm}$ excitation and $\lambda_{\mathrm{em}}=538 \mathrm{~nm}$ emission (Fluoroskan ${ }^{\mathrm{TM}}$ Microplate Fluorometer; Thermo Scientific ${ }^{\mathrm{TM}}$ ).

\section{Activity of Caspases 3/7 and 9}

Caspase-3/7 and 9 enzymatic activities in K-562 cells were assessed using the commercial fluorescent apoptosis system, Apo-ONE ${ }^{\circledR}$ Homogeneous Caspase-3/7 Assay, and luminescent assay, Caspase-Glo ${ }^{\circledR} 9$ Assay (Promega; Madison, USA), respectively. The assays were performed according to the manufacturer's instructions. Cells were seeded (20,000 and 40,000 cells/well, respectively) on 96-well black or white bottom microplates, respectively. The culture medium served as the blank ("background"), untreated cells as the negative control. The positive control was also performed using cells supplemented with cisPt (apoptosis inducer). Cells incubated with cisPt and an inhibitor of caspase activity Z-VAD-FMK (final concentration $20 \mu \mathrm{M}$ ) served as the additional control. The fluorescence was measured at $\lambda_{\mathrm{ex}}=485 \mathrm{~nm}$ excitation and $\lambda_{\mathrm{em}}=538 \mathrm{~nm}$ emission (Fluoroskan ${ }^{\mathrm{TM}}$ Microplate Fluorometer; Thermo Scientific ${ }^{\mathrm{TM}}$ ) after the profluorescent Z-DEVD-R110 substrate addition. Whereas the luminescent signal was read using the Synergy ${ }^{\text {TM }}$ HTX Multi-Mode Microplate Reader (BioTek; Winooski, USA) after the addition of the luminogenic substrate containing the LEHD sequence with a proteasome inhibitor (MG-132).

\section{Statistical Analysis}

All obtained results are presented as mean values \pm SD. Using Shapiro-Wilk test, the normality of the results was analyzed. Then, the non-parametric Levene's test for homogeneity of variance was performed. Based on the Levene's test (ANOVA) followed by post-hoc Tukey's test the differences between values were evaluated. All obtained data were analysed using StatSoft Inc. "Statistica" v. 13.1. The values of $\mathrm{p}<0.05$ are considered to be statistically significant. All presented figures were prepared using GraphPad Prism 5 Software.

\section{Results}

As shown in Figure 1A and B, a significant reduction of the percentage of viable K-562 cells after 24-h culture with the supernatants has been noted, at doses 10 and $20 \% \mathrm{v} / \mathrm{v}$, compared to untreated control cells (by $60-67 \%$; $<<0.001$ ). Moreover, these supernatants' doses significantly augmented the cytotoxic effect of cisPt against K-562 cells. Exposure to $5 \%$ sNLR1 and sNLR42 resulted in an approximately 2-fold slighter cytotoxic effect compared to the control (Figure 1C). Since experiments carried out with $2 \%$ supernatants did not prove statistically significant changes in cell survival (data not shown), the dose of 5\% was finally taken as optimal for further experiments.

Subsequently, the supernatants (sNLR1, sLR1, sLR42) have been found to significantly inhibit (by above 25\%; $\mathrm{p}<0,05$ ) cell proliferation when assessed by BrdU incorporation (Figure 2). Cells cultured in the presence of cisPt and supernatants isolated from unfiltered units of PRBC showed more than 2-fold reduced proliferative capacity $(\mathrm{p}<0.01)$ compared to cells treated with cisPt. Cisplatin alone inhibited the proliferation of K-562 cells by about $50 \%(\mathrm{p}<0.001)$ compared to control.

The amount of intracellular ROS was determined using the $\mathrm{H}_{2}$ DCF-DA fluorescent probe. K-562 cells exposed to sNLR42, sLR1 and sLR42 showed an increased ROS level by 55\% $(\mathrm{p}<0.01), 67 \%(\mathrm{p}<0.01)$ and $42 \%(\mathrm{p}<0.05)$, respectively, compared to untreated cells (Figure 3). In the experimental system in which cells were treated with cisPt, also an increase in ROS levels (by above 30\%; $\mathrm{p}<0.05$ ) was observed in the presence of sNLR42 and sLR1. Cisplatininduced ROS generation in K-562 cells was to a degree approximately $50 \%$ greater than that in control.

The degree of DNA damage (ie single and double-strand breaks and alkali-labile sites) can be detected by the alkaline comet assay. As shown in Figure 4, supernatants from the filtered PRBC units (5\% v/v), especially sLR1, caused above 5 -fold $(\mathrm{p}<0.01)$ increase of the percentage of "tail" DNA compared to control, while higher concentrations $(20 \% \mathrm{v} / \mathrm{v})$ of sNLR1, sLR1, and sLR42 turned out to be more genotoxic for cells (a 6-8-fold increase of the total DNA damage levels).

DNA damage, mostly double-strand breaks, if not repaired, is known to trigger apoptotic cell death. Activities of caspase-3/7 in K-562 cells treated with sNLR1, sNLR42, and sLR1, as well as caspase 9 in cells exposed to sNLR1 and 

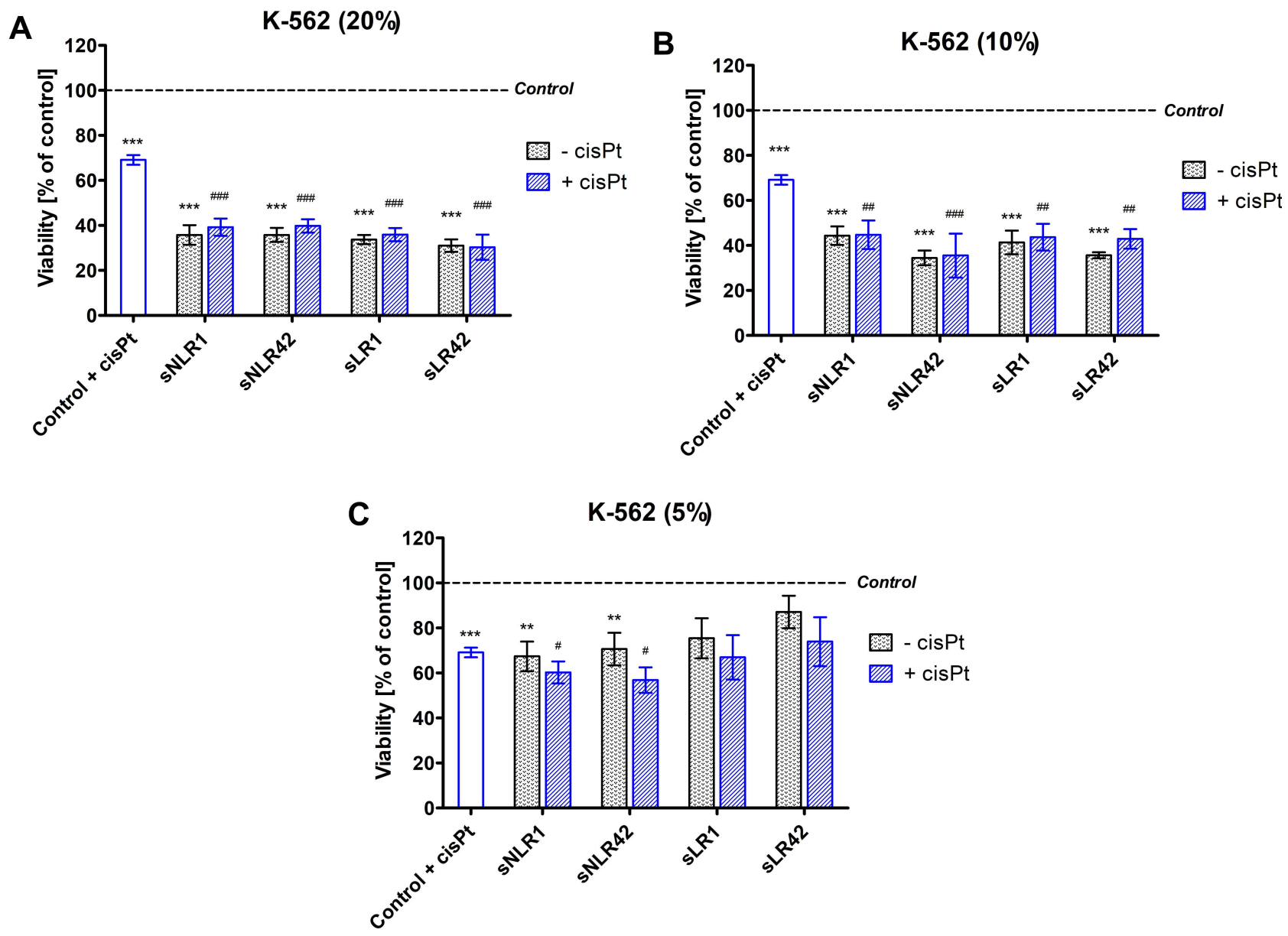

Figure I Viability of K-562 cells after incubation (24 h) with different concentrations of the PRBC supernatants in the absence or presence of cisPt (10 $\mu \mathrm{M})$ evaluated using the CCK-8 assay. The figure shows mean values from 5 independent experiments (A and $\mathbf{B})$ and 10 independent measurements for (C). All data is presented as a percentage of control (untreated cells - assumed as 100\%). Error bars denote $\pm \mathrm{SD} ;{ }^{\#}<0.05$ vs control with cisPt, ${ }^{* *} \mathrm{p}<0.01$ vs control (untreated cells), ${ }^{\#}<<0.01$ vs control with cisPt, **** $\mathrm{p}<0.001$ compared to the appropriate control.

sLR1 were found to be elevated (by approximately $36 \%$; $<0.05$ and above $25 \% ; \mathrm{p}<0.001$ ), respectively (Figure $5 \mathrm{~A}$ and B). The anti-cancer drug cisPt significantly activated caspase-3/7 (by approx. 48\%; $\mathrm{p}<0.05$ ) and caspase-9 (by approx. $40 \%$; $<0.001$ ), while the caspase inhibitor Z-VAD-FMK inhibited their activity. In the presence of cisPt, supernatants from PRBC units on day 1 of storage also increased the activity of both caspase 3/7 and 9 , compared to cells cultured with cisPt alone.

The effect of supernatants on the survival of K-562 cells in the presence of Z-VAD-FMK was determined (CCK-8 assay). The viability of cells cultured in the presence of supernatants and the inhibitor, both with and without cisPt, was similar to that of untreated cells.

\section{Discussion}

Numerous biological mediators (eg as cytokines, eicosanoids, growth factors) that have pro-tumoral activity have been identified in the acellular fraction of PRBC, proposing that it may have tumor-promoting effect, ${ }^{10}$ therefore it was reasonable to hypothesize that PRBC would increase growth and proliferation of cultured cancer cells. Unexpectedly, our studies demonstrate that PRBC supernatants substantially decreased the survival of K-562 cells in a commercial viability assay (Figure 1), and they also inhibited the proliferative capacity of K-562 cells (Figure 2). These cytotoxic effects against the cancer cells were found to be independent on the PRBC ex vivo storage duration and leukocyte depletion. Similar cytotoxic effects have also been noted in the presence of the anti-cancer drug (cisPt). Further, intracellular ROS levels were determined, to clarify whether these could be involved in inhibiting the growth and proliferation of cancer 


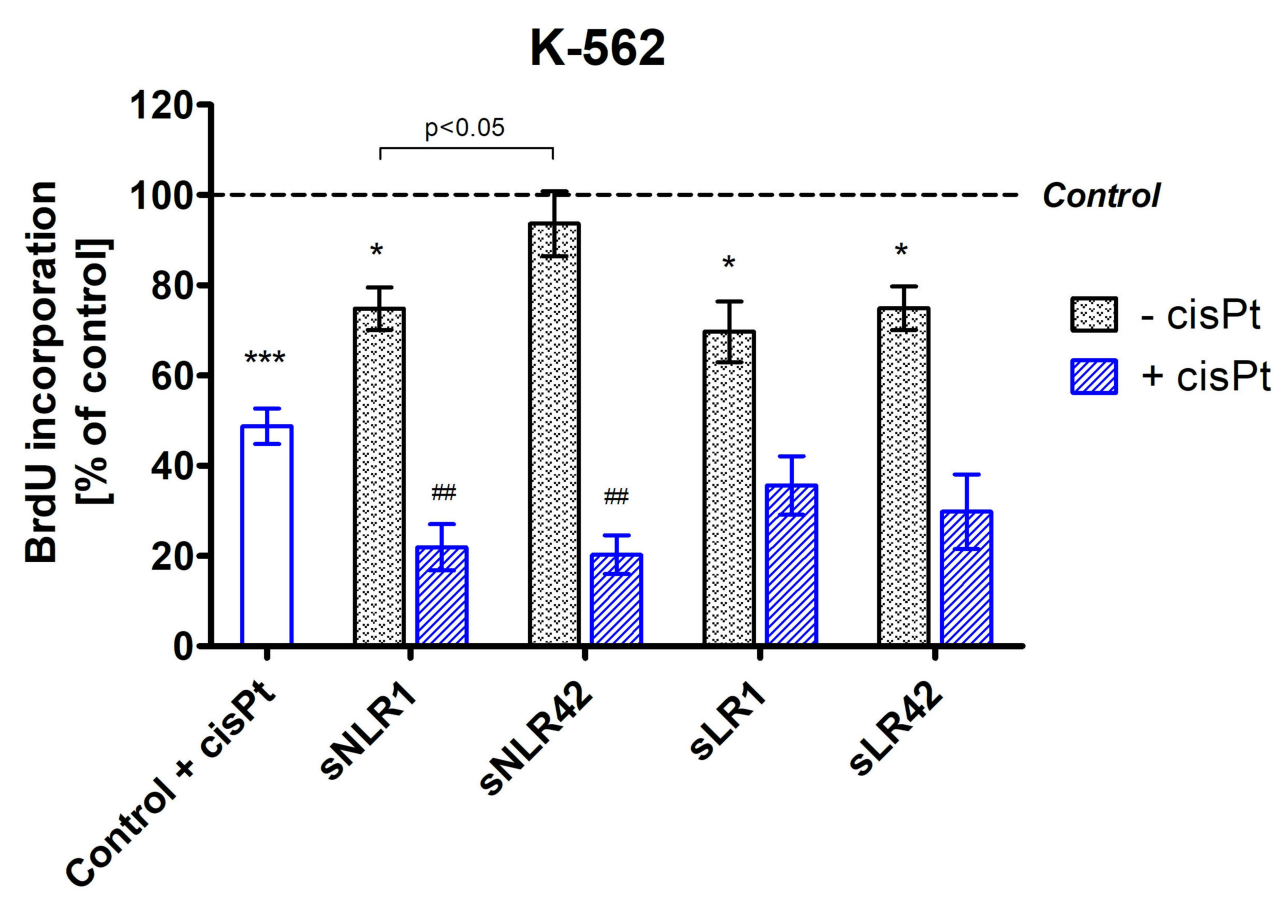

Figure 2 Proliferation of K-562 cells, assessed by the BrdU incorporation during DNA synthesis, after incubation ( $24 \mathrm{~h})$ with the PRBC supernatants ( $5 \%$ ) in the absence or presence of cisPt $(10 \mu \mathrm{M})$. All data is presented as a percentage of control (untreated cells - assumed as I00\%). Error bars denote \pm SD, $n=3$ (independent experiments); ${ }^{*} \mathrm{p}<0.05$ vs control (untreated cells), ${ }^{\#} \mathrm{p}<0.01$ vs control with cisPt, ${ }^{* * *} \mathrm{p}<0.00 \mathrm{I}$ vs control (untreated cells).

cells grown in a medium supplemented with the supernatants $(5 \%)$, which confirmed that indeed the supernatants induced the excessive ROS generation (Figure 3). The elevated ROS in cells may contribute to the development of DNA damage (and other cellular biomolecules) and hyperactivation of ROS signaling pathways leading to cell death. A tendency to



Figure 3 The intracellular ROS level in K-562 cells after incubation $\left(60 \mathrm{~min}, 37^{\circ} \mathrm{C}\right)$ with the PRBC supernatants $(5 \%)$ in the absence or presence of cisPt $(\mathrm{I} 0 \mu \mathrm{M})$. All data is presented as a percentage of control (untreated cells - assumed as $100 \%$ ). Error bars denote \pm SD, $n=3-5$ (independent experiments); $* / \# p<0.05$ compared to the appropriate control, ${ }^{* *} p<0.01$ vs control (untreated cells). 


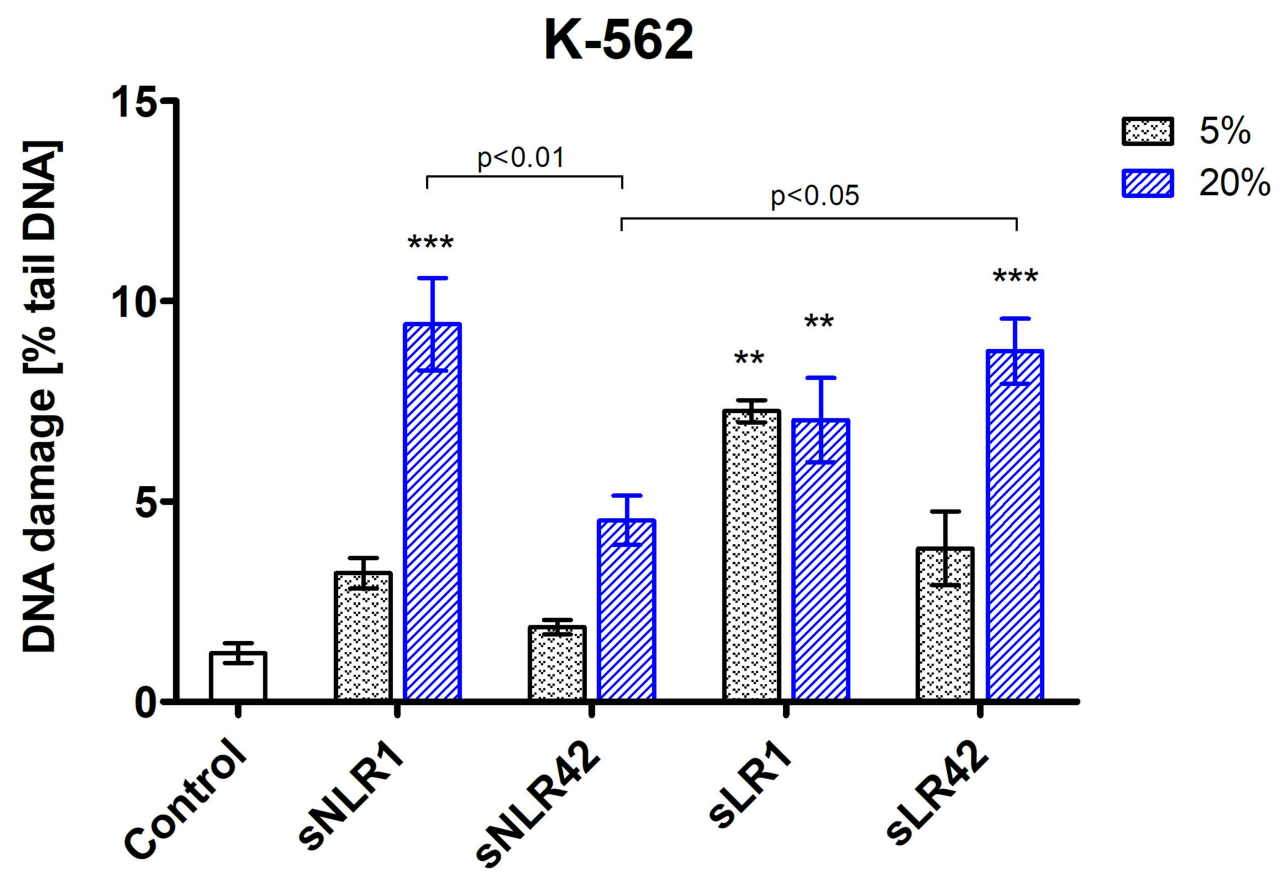

Figure 4 The DNA damage, measured as a percentage of tail DNA in the alkaline comet assay, in $\mathrm{K}-562$ cells pre-incubated for I $\mathrm{h}$ at $37^{\circ} \mathrm{C}$ with the PRBC supernatants $(5 \%$ and $20 \% \mathrm{v} / \mathrm{v}$ ). All experiments included a negative (untreated cells) and positive $(10 \mu \mathrm{M} \mathrm{H} 2 \mathrm{O} 2)$ control. Error bars denote \pm SD, $\mathrm{n}=3$ (independent experiments); ${ }^{* *} \mathrm{p}<0.0 \mathrm{I}$, $* * * p<0.001$ compared to untreated cells.

increases the DNA damage levels after incubation of cells with the lower supernatant concentration (5\%), as well as much stronger genotoxic effect of the supernatants at their higher dose (20\%), were observed (Figure 4).

Many intra- and extracellular factors can regulate the apoptosis process. The elevated levels of DNA damage (mostly double-strand breaks, if not properly repaired by the cellular DNA repair mechanisms) and/or excessive intracellular ROS, among others, are common factors inducing apoptosis. ${ }^{22,23}$ Caspases (cysteine-aspartic proteases) are a family of protease enzymes essential for the execution of programmed cell death. Caspase-9 is involved in the initiation of the apoptotic process in the endogenous mitochondrial pathway. Its activation mediates the excitation of caspase-3 and 7, which act as effectors in the executive phase of the apoptotic process. ${ }^{22,23}$ Supernatants, regardless of the preparation method, both in the presence and absence of cisPt, were shown to enhance the apoptosis (Figure 5A and B), which was additionally confirmed by inhibiting the activity of caspases (CCK-8 assay performed in the presence of Z-VAD-FMK, an inhibitor of caspases) (Figure 5C).

Nowadays, in the era of the second-generation tyrosine kinase inhibitors (TKI), cisPt is not routinely used in the treatment of CML or AML. However, cisPt and its analogues have been widely used in the treatment of various types of human cancer, both as monotherapy and in combination with other drugs. ${ }^{13}$ Cisplatin is also commonly applied in laboratory research as a cytotoxic drug that kills cancer cells by a direct interaction with DNA through the formation of intra-strand bonds that inhibit replication, leading to cell cycle arrest and then apoptosis. ${ }^{13,24}$ Cisplatin-induced DNA damage activates various signaling pathways to prevent or promote cell death. The mechanism of the anti-tumor activity of cisPt is not fully understood. Only $1 \%$ of the cisPt present in a cell has been shown to bind to nuclear DNA. The remaining percentage reacts with membrane and cytoplasm components, which indicates that the drug may also exert a cytotoxic effect through mechanisms independent of nuclear DNA binding, ${ }^{25}$ eg, by inducing the production of ROS. ${ }^{26}$ Our data confirmed the involvement of ROS in the mechanism of the drug cytotoxic action on K-562 cells (Figure 3). Moreover, PRBC supernatants had the slight effect (Figure 1) or potentiated (Figures 2, 3, 5A and B) the cytotoxicity of cisPt against K-562 cells.

The results indicate that one of the possible mechanisms responsible for the cytotoxic effect of the supernatants on K-562 cells is the excessive oxidative stress (OS), which can result from the presence of $\mathrm{Hb}$ degradation products in the PRBC unit. Due to the innovative nature of the study and the lack of appropriate references, the interpretation of the 

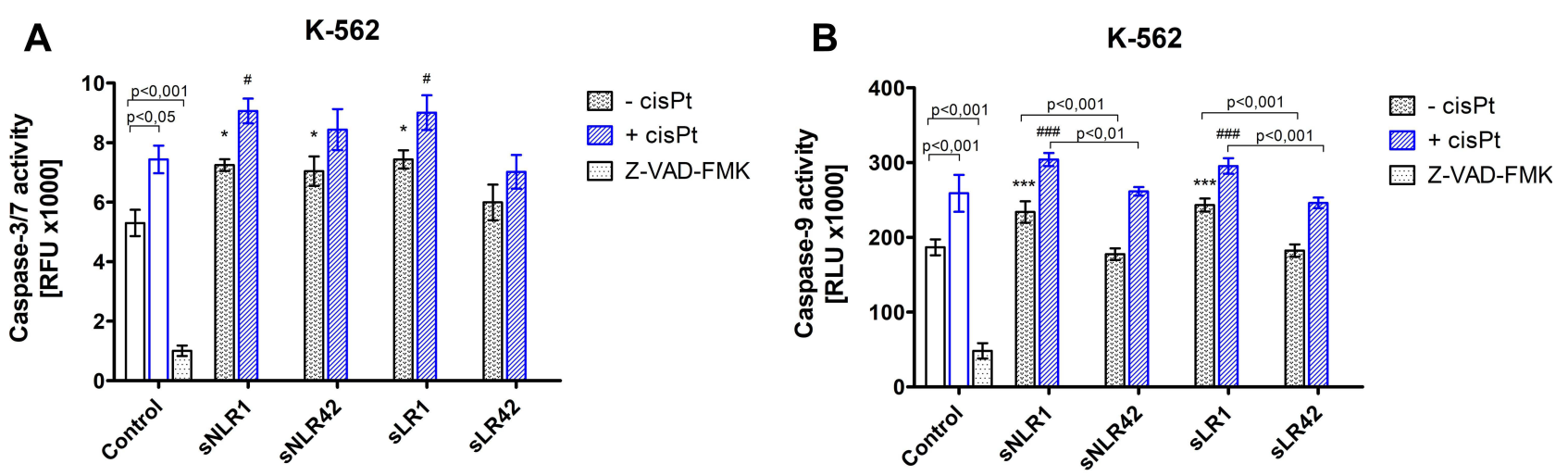

\section{C}

K-562 (Z-VAD-FMK)

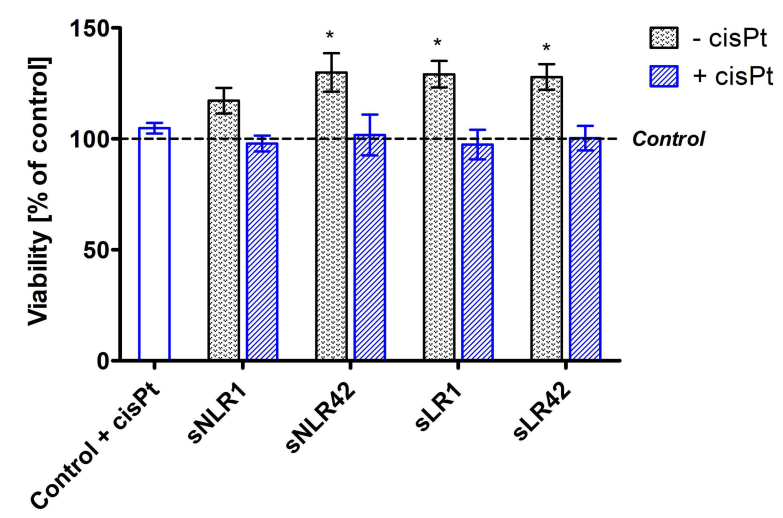

Figure 5 Activities of caspase-3/7 (A) and caspase-9 (B) in K-562 cells treated (24 h) with the PRBC supernatants $(5 \%)$ in the absence or presence of cisPt (I0 $\mu$ M). (C) shows K-562 cells viability in the presence of caspase inhibitor Z-VAD-FMK, PRBC supernatants, and cisPt. Data obtained from viability measurements are presented as a percentage of control (untreated cells - assumed as 100\%). Error bars denote $\pm \mathrm{SD}, \mathrm{n}=3$ (independent experiments); $* \# \mathrm{p}^{\prime \prime}<0.05, * * * \ldots \#+0.00 \mathrm{I}$ compared to the appropriate control.

results and determination of their clinical relevance is difficult. Free $\mathrm{Hb}$, heme, and iron, delivered to the recipient's circulation with the transfused PRBC, are sources of non-transferrin bound iron (NTBI) and may be toxic, ${ }^{27}$ eg by participating in ROS generation. ${ }^{27,28}$ Chronic OS and the accompanying inflammation are well-known factors influencing the progression of neoplastic disease. ${ }^{29}$ Compared to normal cells, cancer cells are characterized by much higher ROS levels, due to, among others, mitochondrial dysfunction and increased metabolism. On the other hand, very high concentrations of intracellular ROS are extremely toxic to cells, which can be used in anti-cancer therapies based on either the inhibition of the cellular antioxidant defense or the enhancement of ROS production. ${ }^{30}$

The role of OS in the progression of hematopoietic malignancies (including CML, AML) has been well documented but is still not fully understood. ${ }^{31}$ Our results remain inconsistent with the data published by Barnett et al ${ }^{15}$ who showed that supernatants of long-stored (unfiltered and filtered) PRBC increased proliferation and migration of mouse pancreatic cancer cells (Pan02), and when administered intravenously contributed to pancreatic cancer progression in mice. The inconsistency with the obtained results may be related to the use of a completely different line of cancer cells, additionally of mouse origin. It is possible that substances present in PRBC supernatants may have different effects in different types of cancer. Moreover, Zhuang et al reported the effect of platelet-derived growth factor (PDGF) and vascular endothelial growth factor (VEGF), accumulating in PRBC, on the proliferation of human hepatocellular carcinoma cells (HepG2). ${ }^{16}$ The authors demonstrated that the supernatants of unfiltered RBCs increased the proliferation of these cells. ${ }^{16}$ The discrepancy between their and our results may result from not only different cell lines used but also from other differences in experimental systems (cells were incubated with supernatants for $48 \mathrm{~h}$ and no information was provided on the amount of supernatant used in the study). In our studies, the incubation time of cells with supernatants 
(24 hours) was selected due to the population doubling time, which in the case of K-562 cells ranged between 18 and 34 hours. This time, however, may have been too short to properly assess the pro-proliferative properties of the supernatants. In all the conducted experiments, a direct influence of SAGM on the tested parameters was excluded. Since we used the syringe filters with a pore size of $0.22 \mu \mathrm{m}$ before freezing the supernatants used in the study, the participation of microparticles in the effect of the supernatants on cells can also be largely excluded. Tayer et al ${ }^{32}$ also used $0.22 \mu \mathrm{m}$ filters in their studies to remove MPs from samples.

Possibly, some antitumorigenic cytokines, ie, interferons, IL-4, IL-6, IL-12, TNF- $\alpha$, TGF- $\beta{ }^{33}$ are also responsible for the cytotoxic effect of the supernatants. These cytokines are pleiotropic and depending on the concentration or stage of the disease, they may have different properties. For example, their low concentrations may initiate the growth of neoplastic cells, and high concentrations inhibit them. In the supernatants of unfiltered RBCs, no effect of storage on the increase of IL- 6 concentration was demonstrated. ${ }^{34}$ The Generally accepted theory of "cytokine fields" in the tumor microenvironment, defining the ratio of the amount of $\mathrm{Th} 2$ and $\mathrm{Th} 3$ cytokines in relation to Th1, allows to some extent to understand the role of these protein mediators in neoplastic diseases. ${ }^{35,36}$

The results of the current study indicate that the storage time of PRBC and leukocyte depletion did not significantly influence the response of K-562 cells to the supernatant. In agreement with these in vitro findings, in the study on patients diagnosed with cancer, Kekre et $\mathrm{al}^{37}$ reported no impact of the transfused PRBC storage duration on OS or cancer recurrence. Filtration does not fully prevent the accumulation of some inflammatory agents in clinically relevant concentrations in the supernatant. Therefore, the presence in supernatants of polyunsaturated fatty acids and their oxidation products, demonstrated both in unfiltered and filtered units, on the 42 day of storage ${ }^{38}$ may be responsible for their cytotoxicity towards K-562 cells. In the fresh PRBC the concentration of 12-HETE (involved in such processes as oxidative stress, inflammation, and neoplastic disease) does not differ between filtered and unfiltered units. ${ }^{39}$

\section{Conclusion}

To sum up, the supernatants in both experimental systems (in the absence and presence of cisPt) promoted apoptosis of K-562 cells via the pro-oxidative effect (increased ROS production and consequently increased genotoxicity), which was manifested by the viability reduction and inhibition of K-562 cell proliferation. No significant influence of the pre-storage leukocytefiltration and storage time of PRBC units on their anti-proliferative effect was demonstrated. These findings may suggest that the PRBC acellular fraction does not affect the CML progression. However, at the current phase of the research our results may not be of much relevance from a clinical point of view. This issue requires further study. One of the important questions remains whether PRBC supernatants can modulate the anti-proliferative effects of other anti-cancer drugs, approved to treatment of AML/CML either in modern therapies (imatinib and other second-generation TKI) or in traditional cytotoxic chemotherapy (anthracycline, cytarabine, omacetaxine, etoposide, cladribine, or fludarabine).

\section{Acknowledgment}

This work was supported by grant no. B1811000001785.02 (University of Lodz).

\section{Disclosure}

The authors report no conflicts of interest in this work.

\section{References}

1. Gilreath JA, Stenehjem DD, Rodgers GM. Diagnosis and treatment of cancer-related anemia. Am J Hematol. 2014;89(2):203-212. doi:10.1002/ ajh. 23628

2. DeZern AE, Williams K, Zahurak M, et al. Red blood cell transfusion triggers in acute leukemia: a randomized pilot study. Transfusion. 2016;56 (7):1750-1757. doi:10.1111/trf.13658

3. Goubran H, Sheridan D, Radosevic J, Burnouf T, Seghatchian J. Transfusion-related immunomodulation and cancer. Transfus Apher Sci. 2017;56 (3):336-340. doi:10.1016/j.transci.2017.05.019

4. Cata JP, Gottumukkala V. Blood transfusion practices in cancer surgery. Indian J Anaesth. 2014;58(5):637-642. doi:10.4103/0019-5049.144675

5. Deeb AP, Aquina CT, Monson JRT, Blumberg N, Becerra AZ, Fleming FJ. Allogeneic leukocyte-reduced red blood cell transfusion is associated with postoperative infectious complications and cancer recurrence after colon cancer resection. Dig Surg. 2020;37(2):163-170. doi:10.1159/000498865 
6. Talukder Y, Stillwell AP, Siu SK, Ho YH. Comparing survival and recurrence in curative stage I to III colorectal cancer in transfused and nontransfused patients. Int Surg. 2014;99(1):8-16. doi:10.9738/INTSURG-D-13-00141.1

7. Qiu L, Wang DR, Zhang XY, et al. Impact of perioperative blood transfusion on immune function and prognosis in colorectal cancer patients. Transfus Apher Sci. 2016;54(2):235-241. doi:10.1016/j.transci.2015.07.004

8. Iqbal N, Haider K, Sundaram V, et al. Red blood cell transfusion and outcome in cancer. Transfus Apher Sci. 2017;56(3):287-290. doi:10.1016/j. transci.2017.05.014

9. Koch CG, Duncan AI, Figueroa P, et al. Real age: red blood cell aging during storage. Ann Thorac Surg. 2019;107(3):973-980. doi:10.1016/j. athoracsur.2018.08.073

10. Cata JP, Wang H, Gottumukkala V, Reuben J, Sessler DI. Inflammatory response, immunosuppression, and cancer recurrence after perioperative blood transfusions. Br J Anaesth. 2013;110(5):690-701. doi:10.1093/bja/aet068

11. Silliman CC, Burke T, Kelher MR. The accumulation of lipids and proteins during red blood cell storage: the roles of leucoreduction and experimental filtration. Blood Transfus. 2017;15(2):131-136. doi:10.2450/2017.0314-16

12. McWhirter JR, Wang JY. Activation of tyrosinase kinase and microfilament-binding functions of c-abl by bcr sequences in bcr/abl fusion proteins. Mol Cell Biol. 1991;11(3):1553-1565. doi:10.1128/mcb.11.3.1553-1565.1991

13. Dasari S, Tchounwou PB. Cisplatin in cancer therapy: molecular mechanisms of action. Eur J Pharmacol. 2014;740:364-378. doi:10.1016/j. ejphar.2014.07.025

14. Xiao LY, Kan WM. Poly ADP-ribose polymerase inhibition suppresses cisplatin toxicity in chronic myeloid leukemia cells. Anticancer Drugs. 2017;28(3):316-321. doi:10.1097/CAD.0000000000000467

15. Barnett CC Jr., Beck AW, Holloway SE, et al. Intravenous delivery of the plasma fraction of stored packed erythrocytes promotes pancreatic cancer growth in immunocompetent mice. Cancer. 2010;116(16):3862-3874. doi:10.1002/cncr.25140

16. Zhuang Y, Zhang T, Wei C, et al. Effect of storage time on cumulation of platelet-related growth factors in the supernatant of leukoreduced packed red cells and tumor cell proliferation in vitro. Zhongguo shi yan xue ye xue za zhi. 2015;23(2):541-545. doi:10.7534/j.issn.1009-2137.2015.02.048

17. Westerman M, Pizzey A, Hirschman J, et al. Microvesicles in haemoglobinopathies offer insights into mechanisms of hypercoagulability, haemolysis and the effects of therapy. Br J Haematol. 2008;142(1):126-135. doi:10.1111/j.1365-2141.2008.07155.x

18. Singh NP, McCoy MT, Tice RR, Schneider EL. A simple technique for quantitation of low levels of DNA damage in individual cells. Exp Cell Res. 1988;175(1):184-191. doi:10.1016/0014-4827(88)90265-0

19. Klaude M, Eriksson S, Nygren J, Ahnstrom G. The comet assay: mechanisms and technical considerations. Mutat Res. 1996;363(2):89-96. doi:10.1016/0921-8777(95)00063-1

20. Czubatka A, Sarnik J, Lucent D, Blasiak J, Witczak ZJ, Poplawski T. A novel carbohydrate derived compound FCP5 causes DNA strand breaks and oxidative modifications of DNA bases in cancer cells. Chem Biol Interact. 2015;227:77-88. doi:10.1016/j.cbi.2014.12.023

21. Balcerczyk A, Soszynski M, Rybaczek D, et al. Induction of apoptosis and modulation of production of reactive oxygen species in human endothelial cells by diphenyleneiodonium. Biochem Pharmacol. 2005;69(8):1263-1273. doi:10.1016/j.bcp.2005.01.010

22. Rudnicka KW, Szczęsna E, Miszczyk E, Mikołajczyk-Chmiela M. Apoptoza i Autofagia Mechanizmy i Metody Detekcji [Apoptosis and autophagy mechanisms and detection methods]. Post Biol Kom. 2011;38(2):247-265. Polish.

23. Zapolska-Downar D, Sygitowicz G, Jarosz M. Znaczenie apoptozy w patogenezie miażdżycy [Role of apoptosis in the pathogenesis of atherosclerosis]. Kardiol Pol. 2008;66(10):347-357. Polish.

24. Kozakiewicz B, Kaczmarczyk M. Cisplatyna - lek z przypadku [Cisplatin - a "by-chance” drug]. Curr Gynecol Oncol. 2012;10(2):131-140. Polish.

25. Sarin N, Engel F, Kalayda GV, et al. Cisplatin resistance in non-small cell lung cancer cells is associated with an abrogation of cisplatin-induced G2/M cell cycle arrest. PLoS One. 2017;12(7):e0181081. doi:10.1371/journal.pone.0181081

26. Brozovic A, Ambriovic-Ristov A, Osmak M. The relationship between cisplatin-induced reactive oxygen species, glutathione, and BCL-2 and resistance to cisplatin. Crit Rev Toxicol. 2010;40(4):347-359. doi:10.3109/10408441003601836

27. Baron DM, Lei C, Berra L. Old, older, the oldest: red blood cell storage and the potential harm of using older red blood cell concentrates. Curr Opin Anaesthesiol. 2020;33(2):234-239. doi:10.1097/ACO.000000000000824

28. Rapido F, Brittenham GM, Bandyopadhyay S, et al. Prolonged red cell storage before transfusion increases extravascular hemolysis. J Clin Invest. 2017;127(1):375-382. doi:10.1172/JCI90837

29. Agudelo-Jimenez RD, Heatter JA, Cata JP. Transfusion therapy: Is there a link with cancer recurrence? Curr Anesthesiol Rep. $2018 ; 8(4)$ :426-438. doi:10.1007/s40140-018-0292-3

30. Udensi UK, Tchounwou PB. Dual effect of oxidative stress on leukemia cancer induction and treatment. J Exp Clin Cancer Res. 2014;33(1):1-15. doi:10.1186/s13046-014-0106-5

31. Pascu EG, GĂMan M-A, Moisă C, Assani AD, GĂMan AM. The involvement of oxidative stress in chronic myeloid leukemia. Rom Biotechnol Lett. 2020;25(1):1267-1274. doi:10.25083/rbl/25.1/1267.1274

32. Tayer AH, Amirizadeh N, Ahmadinejad M, Nikougoftar M, Deyhim MR, Zolfaghari S. Procoagulant activity of red blood cell-derived microvesicles during red cell storage. Transfus Med Hemother. 2019;46(4):224-230. doi:10.1159/000494367

33. Berraondo P, Sanmamed MF, Ochoa MC, et al. Cytokines in clinical cancer immunotherapy. Br J Cancer. 2019;120(1):6-15. doi:10.1038/s41416-018-0328-y

34. Kristiansson M, Soop M, Saraste L, Sundqvist KG. Cytokines in stored red blood cell concentrates: promoters of systemic inflammation and simulators of acute transfusion reactions? Acta Anaesthesiol Scand. 1996;40(4):496-501. doi:10.1111/j.1399-6576.1996.tb04475.x

35. Tzounakas VL, Seghatchian J, Grouzi E, Kokoris S, Antonelou MH. Red blood cell transfusion in surgical cancer patients: targets, risks, mechanistic understanding and further therapeutic opportunities. Transfus Apher Sci. 2017;56(3):291-304. doi:10.1016/j.transci.2017.05.015

36. Chechlińska M. Rola cytokin w procesach nowotworzenia [The role of cytokines in carcinogenesis]. Nowotwory J Oncol. 2003;53(6):648-659. Polish.

37. Kekre N, Mallick R, Allan D, Tinmouth A, Tay J. The impact of prolonged storage of red blood cells on cancer survival. PLoS One. 2013;8(7): e68820. doi:10.1371/journal.pone.0068820

38. Fu X, Felcyn JR, Odem-Davis K, Zimring JC. Bioactive lipids accumulate in stored red blood cells despite leukoreduction: a targeted metabolomics study. Transfusion. 2016;56(10):2560-2570. doi:10.1111/trf.13748

39. Porro B, Songia P, Squellerio I, Tremoli E, Cavalca V. Analysis, physiological and clinical significance of 12-HETE: a neglected platelet-derived 12-lipoxygenase product. J Chromatogr B Analyt Technol Biomed Life Sci. 2014;964:26-40. doi:10.1016/j.jchromb.2014.03.015 


\section{Publish your work in this journal}

The Journal of Blood Medicine is an international, peer-reviewed, open access, online journal publishing laboratory, experimental and clinical aspects of all aspect pertaining to blood based medicine including but not limited to: Transfusion Medicine; Blood collection, Donor issues, Transmittable diseases, and Blood banking logistics; Immunohematology; Artificial and alternative blood based therapeutics; Hematology; Biotechnology/nanotechnology of blood related medicine; Legal aspects of blood medicine; Historical perspectives. The manuscript management system is completely online and includes a very quick and fair peer-review system. Visit http://www.dovepress.com/testimonials.php to read real quotes from published authors.

Submit your manuscript here: http://www.dovepress.com/journal-of-blood-medicine-journal 